\title{
The Failure of Saganomics: \\ Why Birth Models Cannot Explain Near-Death Phenomena
}

\author{
Carl B. Becker \\ Department of Philosophy \\ Southern Illinois University
}

\begin{abstract}
A number of recent studies have tended to demonstrate that deathbed visions of "figures of light" are found in many cultures, regardless of religious training or conviction. In a widely cited hypothesis, Carl Sagan has proposed that this universality is due to man's recollections of his birth experiences. This paper brings the findings of psychologists and reasoning of philosophers to bear on this question, refuting Sagan's theory in three areas. (1) If birth analogies render NDEs meaningless, then they also render meaningless the scientific theories that Sagan finds analogous to birth experiences. (2) Newborn babies cannot perceive nor remember well enough to form images of the sort perceived at deathbeds (much research is cited to document this claim). (3) The birth experience is not analogous to NDEs, in several important respects. We may conclude that NDEs are not psychological "replays" of our birth experiences; we must look elsewhere for an understanding of their universality. This question, with all of its philosophical ramifications, is shown to be emphatically open to contributions of empirical research.
\end{abstract}

In recent years, the study of the question of survival - the continuity of personal consciousness after death - has become increasingly prominent in both psychological and philosophical journals and conferences. There is a growing acceptance that we may formulate meaningful (i.e. falsifiable) hypotheses about the occurrence and nature of survival, and gain some understanding of its possibilities and difficulties, through empirical studies. Clinical as well as anecdotal studies of near-death experiences have become widely known. Deathbed experiences have been popularly characterized as including the feelings of going through a long tunnel towards a "figure of light" and emerging into heavenly fields. The fact that many people have these sorts of experiences is now too widely established to be questioned, but the origins, meanings, and ontological status of these experiences are still widely debated by philosophers and psychologists. Among the most central questions to be answered here is whether the "objects" of these experiences are in any sense "real," or whether they should better be regarded as purely nonreferential hallucinations lacking both veridicality and meaning. 
The earliest of the attacks against the veridicality of near-death experiences (NDEs) was the allegation that NDEs simply reflect the religious beliefs of the people who experience them. Empirical studies have refuted this claim from several standpoints. Agnostics and atheists have had visions of "heaven" or religious figures, while devout churchgoers expecting judgment or purgatory found none (Ring, 1980). The cultural expectations that (a) there is no life after death, or (b) pain is as likely as pleasure in the next world (especially for sinners or non-believers) were simply not reflected in NDEs either (Ring, 1980). So NDEs cannot be written off as mere projections of one's beliefs, desires, or cultural training. The cross-cultural uniformity among Christians, Jews, and Hindus also seems to indicate that more than a cultural image is being seen here; there are elements of broad similarity among many near-death experiencers (Kalish, 1979).

Astronomer Carl Sagan, famous for his studies of Venus, believes that he has the solution to this universality of NDEs. He asserts that the death experience is likely to produce common images of light and tunnels because we have all been through tunnels into light before at birth. This leaves an indelible imprint on our brains that is replayed during the traumatic moments when we face death. In Sagan's words:

The only alternative, so far as I can see, is that every human being, without exception, has already shared an experience like that of those travelers who return from the land of death: the sensation of flight; the emergence from darkness into light; an experience in which, at least sometimes, a heroic figure can be dimly perceived, bathed in radiance and glory. There is only one common experience that matches this description. It is called birth $(1979$, p. 304).

Sagan goes on to reduce all religion and speculative science to an analogue of the birth experience. He sees the satori or nirvana of Eastern religions as no more than a desire for a return to the warm, selfless, undifferentiated state inside the womb. He asks whether "Western fascination with punishment and redemption [might not] be a poignant attempt to make sense of perinatal Stage 2." In Sagan's summary:

If religions are fundamentally silly, why is it that so many people believe in them? . . The common thread is birth. Religion is fundamentally mystical, the gods inscrutable, the tenets appealing but unsound because, I suggest, blurred perceptions and vague premonitions are the best that the newborn infant can manage. It is rather a courageous if flawed attempt to make contact with the earliest and most profound experience of our lives (1979, p. 309). 
Finally Sagan goes on to analogize scientific theories about the universe to the birth experience: steady state theories are analogous to the womb state; oscillating universe theories are analogous to the uterine contraction state; the Big Bang theories are analogous to birth into an ever-widening world. He concludes that our "perinatal" experiences may determine not only our NDEs but our psychiatric predispositions to scientific cosmologies (Sagan, 1979).

A number of things need to be said about Sagan's theory, since it appears superficially seductive and is couched in striking language in a best-selling book. It is trivially true that everything is either in a steady state, shrinking, or growing; thus, everything can be analogized to uterine states, contractions, and birth. But this does not mean that there is any real connection between uterine states and whatever is analogized to them. Sagan shows gross naiveté in equating cosmologi$\mathrm{cal}$ and psychological models, and then attempting to reduce them both to analogies of the birth experience. Apparently the only source for his flights of analogistic imagination is the work of Stanislav Grof, who found some analogies among mystic, drug, and NDE consciousnesses, particularly in their "vision of light" (1975). Grof, while seeking causal explanations for NDEs within brain functions, is careful not to reduce NDEs to nonreferential hallucinations. On the contrary, he leaves open the possibility that changes in brain chemistry set up altered states of consciousness that give access to alternate realities not recognized in our ordinary waking states of mind (cf. Ring, 1980). Grof allows that NDEs and other altered states of consciousness may show us something about other realities, but Sagan crudely reduces all such visions to foggy-headed attempts to remember our own births. This reduction is invalid for three reasons:

(1) There is a further consequence of Sagan's theory, which even he would reject. Sagan says that since NDEs are analogous to the birth experience, they can be reduced to memories of birth, and therefore have no independent [ontologically real] referents. He also says that the universe studied by astronomers is analogous to the birth experience, and that the Big Bang theory he accepts may be a superimposition of our birth memories on our views of the universe. But if such analogies make NDEs non-referential, they should render his Big Bang theories equally non-referential. If they make NDEs into meaningless delusions, then they should also make the Big Bang theory a meaningless delusion. By Sagan's own line of reasoning, science is not finding the truth about the universe, nor do laws of science refer to anything but projections of the birth experiences of the leading scientists. Sagan almost admits this himself when he says: 
I suppose it is too much to hope that the originators of the Steady State hypothesis were born by Caesarean section. But the analogies are very close $(1979$, p. 313).

He tries to find psychological origins for all of his opponents' theories without realizing that the same criticisms must apply to himself, if true. If his theory is true, all the highly touted objectivity of science and scientists is a myth, reducible to the manner of their births and the predilections born thereof.

(2) More scientifically, infants simply cannot perceive anything well enough for Sagan's theory to hold true. The key point in Sagan's analogy between birth and NDEs is that both include the vision of "some godlike figure surrounded by a halo of light - the Midwife or the Obstetrician or the Father" (1979, p. 306). But if newborn infants do not perceive such figures of light, then it is impossible to ascribe NDEs to such infantile perceptions. To examine this claim, we need to turn to the results of extensive studies of infant perception and memory. The limitations on infant perception are indeed substantial, for at birth, many neurons are not in their proper layers, and there are no Nissl bodies or neurofibrils, little chromophil or myelin, and macula are still underdeveloped (Maurer, 1975). Studies have demonstrated visual limitations in numerous areas:

(a) Newborns cannot see in the sense of distinguishing figures in any significant degree (Rugh and Shettles, 1971). Even infants a month old show no response to a difference of less than a 70 percent contrast between dark and light (Braddock and Atkinson, 1979). They cannot focus nor fixate, and when they attempt to do so, they take in only a very small fragment of a total image for only a very short time (Dayton, Jones, Aiu, et al, 1964; Dayton, Jones, Stecle, et al, 1964). They cannot distinguish patterns from backgrounds (Hochberg, 1968, 1970), nor can they recognize features or figures at all (Salapatek, 1968). Half of all newborns cannot coordinate their vision at all on objects an arm's length away; no infants as much as a month old can fully coordinate their vision at five feet (Braddock and Atkinson, 1979).

(b) There is no stability to the images infants perceive. Infants cannot make sense of images that do not hold perfectly still with respect to their eyes for at least two or three seconds (Maurer, 1975). When it is almost impossible for a trained adult to hold a camera still for even a second, the difficulty of holding an object still in relation to the infant's eyeballs for several seconds becomes apparent. The problem is intensified when it is found that infants' eye movements are "rapid and disorganized, especially when crying" (Schulman, 
1973, pp. 76-78), as most infants are doing when they are born. Only half of such infants can track even a slow-moving object for even a few seconds (Dayton, 1964). Thus infant visual perception is not only blurry but fragmentary.

(c) Another problem with infant perception is alertness. The infant's eyes are generally blurred by tears. They are often closed, either from relaxation, napping, or blinking. Even if their eyes are open and free from tears, they are often completely devoid of attention, like the adult who may be momentarily oblivious of his physical surroundings even when his eyes are open (Fantz and Miranda, 1975). Due to these low alertness levels, even infants with the physical capabilities of perceiving blurry patches of light and dark for several seconds at a stretch may completely fail to do so, due to neurological immaturity (Karmel and Maisel, 1975).

(d) Newborns have no conceptual framework into which to fit their scattered visual images. In medical terms, the newborn has little capacity for encoding and can only learn perceptually through laborious investigation, primarily by feeling and tasting objects (Salapatek, 1975). The adult's reliance on sight over taste and touch is a skill developed only after time and discipline. Moreover, infants cannot take in wide scenes all at once or even focus on figures as broad as a human figure (Maurer, 1975). Young babies use only what is known as corner-scan focussing. That is, when they focus at all, it is not on a face or body but usually only on one extremely close corner of a highly contrasting object - often the mother's chin or hair. Full-face recognition is usually not perfected for several months and is certainly impossible at birth (Salapatek, 1975).

(e) Infants have little visual memory of either shape or pattern, as confirmed by experiments (Salapatek, 1975). This helps to explain why we do not remember our early days - or even years - in visual imagery. Even if there were some sort of hidden memory ability in newborn infants (which experiments deny), we should expect that such memories would be almost inconceivably varied and not uniform as Sagan suggests (Cohen and Gelber, 1975). Some babies are born with their eyes open; others, eyes closed. Some fixate momentarily on contrasting stationary objects at close range, like a nipple or forceps; others might never have a stable attentive moment, and all is a chaotic blur. Some are born in even light, some under spotlights, and some in virtual darkness. Some begin to sense lightdark contrasts, while others fail to recognize even this distinction. Some have feeling for color or motion; others are relatively colorblind and unable to track moving objects at all. The possible combin- 
ations are so endless that even if infants all stored their birth experiences in memory, their "playbacks" should hardly be expected to resemble each other at all except in rare coincidences. Sagan's thesis assumes that infants can discern whole figures, with relative integrity and stability, in a certain part of their visual field, but the evidence above is alone adequate to show that his theory is unfounded.

(3) Even if infants were able to perceive their surroundings with any kind of completeness or uniformity at birth, the birth experience and death experiences we are concerned with are not analogous enough to reduce NDEs to memories of birth. Let us review just a few of the more striking dissimilarities between NDEs and what an infant would perceive even if it were possible for him to register images stably and consistently (as he cannot).

(a) Sagan suggests that the birth canal would look like a long dark tunnel with a light at the end. This takes the word "canal" too literally. The baby's head presses tight against the lips of the uterus, allowing no light into the womb. The birth is more analogous to breaking through a membrane from a dark room into a lighter room, or to surfacing from a muddy swimming hole, than to peering down a long tunnel with a glowing light at the other end. Moreover, even if the opening did let light in, the baby is unable to tilt either his head or his eyes upwards to see it (Jones, 1926). If the light registered at all on the untrained brains of the infants, it should be remembered as light streaming in from cracks at the top of their visual ficld, and not as images in which the recipient is looking forward down a long tunnel.

(b) Sagan suggests that the figure of the midwife or doctor may be taken for the "figure of light": heroic, loving, and surrounded by a halo of light. We have already seen that the baby could not possibly focus on such a figure as his doctor or midwife, but if he could, would the figure seem heroic and haloed? The figure would more likely seem a clinical torturer, holding him upside down by the feet, spanking him, cutting his connection with his womb and food supply, putting silver nitrate in his eyes and strapping bands around his ankles. Nor is there any reason that the doctor or midwife should appear substantially brighter (glowing) or darker (haloed) than the surrounding room or background.

(c) Sagan's analogies are predominantly concerned with three features: the tunnel with light at the end, a sensation of flight, and a dimly perceived "figure of light." None of these characterizations, however, correspond to the most important NDEs indicative of survival. In survival-related NDEs we expect visions of either deceased 
friends and relatives, or religious figures, or heavenly imagery of flowers, fields, paths, or boundaries (Osis and Haraldsson, 1977). Even if Sagan's reconstruction of the birth experience were to explain visions of tunnels, lights, flying, and a "fuzzy-figured light," it manifestly fails to explain the sharp and detailed visions with which we are concerned. Clear and distinct deathbed visions of dead relatives, of St. Jerome in friar's hood, or of Jesus with a bloodied chest, are neither explained nor refuted by Sagan's imagination (Ring, 1980).

Lest it seem that we have devoted undue attention to such an indefensible theory, it should be noted that this "amniotic universe" theory of Sagan's has wide popular appeal, both for its superficial understandability, its purported explanatory power, and for the charismatic character of its popularizer in the media. This exercise may also serve to demonstrate that questions concerning the nature of near-death experiences are indeed amenable to empirical investigation - or at least that studies by clinical neurophysiologists and behavioral psychologists have a useful role here - and that much remains to be done in this field before we can adequately interpret the "figure of light" phenomena in near-death experiences.

\section{REFERENCES}

Braddock, O., and Atkinson, J. Accommodation and acuity in the human infant. In R.D. Freeman (Ed.), Developmental Biology of Vision. New York: Plenum, 1979.

Cohen, L.B., and Gelber, E.R. Infant visual memory. In L.B. Cohen and P. Salapatek (Eds.), Infant Perception, Vol. I. New York: Academic Press, 1975.

Dayton, G.O., Jr. Analysis of characteristics of fixation reflex in infants by use of direct current electro-oculography. Neurology, $1964,14,1152-1156$.

Dayton, G.O., Jr., Jones, M.H., Aiu, P., Rawson, R.A., Steele, B., and Rose, M. Developmental study of coordinated eye movements in the human infant. I. Visual acuity in the newborn human. Archives of Ophthalmology, 1964, 71, 865-870.

Dayton, G.O., Jr., Jones, M.H., Steele, B., and Rose, M. Developmental study of coordinated eye movements in the human infant. II. An electro-oculographic study of the fixation reflex in the newborn. Archives of Ophthalmology, 1964, 71, 871-875.

Fantz, R.L., and Miranda, S.B. Newborn infant attention to form of contour. Child Development, 1975, 46, 224-228. 
Grof, S. Realms of the Human Unconscious. New York: Viking, 1975. Hochberg, J. In the mind's eye. In R.N. Haber (Ed.). Contemporary Theory and Research in Visual Perception. New York: Holt, 1968. Hochberg, J. Attention, organization and consciousness. In D. Mostofsky (Ed.), Attention: Contemporary Theory and Analysis. New York: Appleton, 1970.

Jones, M. The development of early behavior patterns in young children. Pedagogical Seminary and Journal of Genetic Psychology. 1926, 33, 537-585.

Kalish, R.A. Contacting the dead: does group identification matter? In R. Kastenbaum (Ed.), Between Life and Death. New York: Springer, 1979.

Karmel, B.A., and Maisel, E.G. A neuronal activity model for infant visual attention. In L.B. Cohen and P. Salapatek (Eds.), Infant Perception, Vol. I. New York: Academic Press, 1975.

Maurer, D. Infant visual perception: methods of study. In L.B. Cohen and P. Salapatek (Eds.), Infant Perception, Vol. I. New York: Academic Press, 1975.

Osis, K., and Haraldsson, E. At the Hour of Death. New York: Avon, 1977.

Ring, K. Life at Death. New York: Coward, McCann, and Geoghegan, 1980.

Rugh, R., and Shettles, L.B. From Conception to Birth, Vol. I. New York: Academic Press, 1971.

Sagan, C. Broca's Brain. New York: Random House, 1979.

Salapatek, P. Visual scanning of geometric figures by the human newborn. Journal of Comparative and Physiological Psychology, 1968, 66, 247-257.

Salapatek, P. Pattern perception in early infancy. In L.B. Cohen and P. Salapatek (Eds.), Infant Perception, Vol. I. New York: Academic Press, 1975.

Schulman, C. Eye movements in infants using direct current recording. Neuropaediatrie, 1973, 4, 76-86.

Requests for reprints to:

Carl B. Becker

Department of Philosophy

Southern Illinois University

Carbondale, Illinois 62901 